\title{
INTRACELLULAR PROLIFERATION OF S. AUREUS IN OSTEOBLASTS AND EFFECTS OF RIFAMPICIN AND GENTAMICIN ON $S$. AUREUS INTRACELLULAR PROLIFERATION AND SURVIVAL
}

\author{
W. Mohamed ${ }^{1}$, U. Sommer ${ }^{1}$, S. Sethi², E. Domann², U. Thormann ${ }^{1,3}$, I. Schütz ${ }^{1}$, K.S. Lips ${ }^{1}$, T. Chakraborty ${ }^{2}$, \\ R. Schnettler ${ }^{1,3}$ and V. Alt $1,3, *$
}

${ }^{1}$ Laboratory of Experimental Trauma Surgery Giessen, Justus-Liebig-University Giessen, 35394 Giessen, Germany ${ }^{2}$ Institute of Medical Microbiology, University Hospital of Giessen-Marburg, Campus Giessen, 35392 Giessen, Germany

${ }^{3}$ Department of Trauma Surgery Giessen, University Hospital of Giessen-Marburg, Campus Giessen, 35385 Giessen, Germany

\begin{abstract}
Staphylococcus aureus is the most clinically relevant pathogen regarding implant-associated bone infection and its capability to invade osteoblasts is well known. The aim of this study was to investigate firstly whether S. aureus is not only able to invade but also to proliferate within osteoblasts, secondly to delineate the mechanism of invasion and thirdly to clarify whether rifampicin or gentamicin can inhibit intracellular proliferation and survival of $S$. aureus. The SAOS-2 osteoblast-like cell line and human primary osteoblasts were infected with $S$. aureus EDCC5055 and S. aureus Rosenbach 1884. Both $S$. aureus strains were able to invade efficiently and to proliferate within human osteoblasts. Immunofluorescence microscopy showed intracellular invasion of $S$. aureus and transmission electron microscopy images could demonstrate bacterial division as a sign of intracellular proliferation as well as cytosolic bacterial persistence. Cytochalasin D, the major actin depolymerisation agent, was able to significantly reduce $S$. aureus invasion, suggesting that invasion was enabled by promoting actin rearrangement at the cell surface. $7.5 \mu \mathrm{g} / \mathrm{mL}$ of rifampicin was able to inhibit bacterial survival in SAOS-2 cells with almost complete elimination of bacteria after $4 \mathrm{~h}$. Gentamicin could also kill intracellular S. aureus in a dose-dependent manner, an effect that was significantly lower than that observed using rifampicin. In conclusion, $S$. aureus is not only able to invade but also to proliferate in osteoblasts. Invasion seems to be associated with actin rearrangement at the cell surface. Rifampicin is effective in intracellular eradication of $S$. aureus whereas gentamicin only poorly eliminates intracellularly replicating bacteria.
\end{abstract}

Keywords: Staphylococcus aureus, osteoblasts, infection, intracellular proliferation, rifampicin, gentamicin.

\author{
*Address for correspondence: \\ Volker Alt \\ Laboratory of Experimental Trauma Surgery Giessen \\ Justus-Liebig-University Giessen \\ D-35394 Giessen, Germany
}

Telephone Number: +49 (0)641 / 98544601

FAX Number: +49 (0)641 / 98544609

E-mail: volker.alt@chiru.med.uni-giessen.de

\section{Introduction}

$S$. aureus is the most frequently isolated pathogen in implant-associated bone infection (Barth et al., 2011). Although $S$. aureus was categorised as an extracellular pathogen due to its ability to colonise extracellular bone matrix and to form biofilm, there is a large body of evidence indicating that $S$. aureus can also internalise and survive within host cells thus acting as a facultative intracellular pathogen (Ellington et al., 2001; Fraunholz and Sinha, 2012; Hamza et al., 2013). This behaviour was implied as an immune-evasion strategy to escape extracellular host antibacterial defence mechanisms such as recognition by professional phagocytes, antibodies, cationic peptides and subsequently treatment with antibiotics. Consequently, such an immune-evasion strategy plays a significant role in persistence and recurrence of infection (Shi and Zhang, 2012). The common bacterial internalisation process requires the involvement of cytoskeletal elements, including actin microfilaments, microtubules and clathrincoated pits. In this context, actin microfilaments play a significant role in the invasion process (Shi and Zhang, 2012). S. aureus uses its adhesins, mainly fibronectin binding proteins A and B (FnBPA, FnBPB), to invade nonprofessional phagocytes such as epithelial and endothelial cells, fibroblasts, osteoblasts and keratinocytes (Jevon et al., 1999; Ahmed et al., 2001; Kintarak et al., 2004; Edwards et al., 2011) by a zipper-type mechanism through fibronectinbridging between FnBPs and $\alpha 5 \beta 1$ integrins on the host cell surface (Shina et al., 2000). Furthermore, the ability of $S$. aureus to persist in an intracellular compartment has been attributed to the formation of small colony variants (SCVs) that show increased uptake by non-professional phagocytes, resistance to intracellular defences, and reduced stimulation of host defences (Sendi and Proctor, 2009). Internalised $S$. aureus could subsequently escape from the endocytic vesicle into the host cell cytosol through the action of the pore-forming $\alpha$-haemolysin under the control of the accessory gene regulator, agr (Jarry et al., 2008). Although many studies have focused on the invasion of epithelial cells by $S$. aureus, little is known about its further proliferation and survival in the intracellular milieu.

The intracellular invasion of $S$. aureus is a virulence factor to escape antibiotic treatment (Kreis et al., 2013). Gentamicin and rifampicin are important antibiotic agents in the treatment of implant-related $S$. aureus infections. Gentamicin was previously shown to be able to kill the 
facultative intracellular bacterium Listeria monocytogenes in the intracellular compartment of mouse peritoneal macrophages only when it was used in concentrations of at least $50 \mu \mathrm{g} / \mathrm{mL}$ (Drevets et al., 1994). Moreover, a concentration of $10 \mu \mathrm{g} / \mathrm{mL}$ gentamicin was not sufficient for rapid eradication of intracellular $S$. aureus from human osteoblasts. However, $7.5 \mu \mathrm{g} / \mathrm{mL}$ rifampicin was able to control intracellular $S$. aureus survival $20 \mathrm{~h}$ after infection (Kreis et al., 2013).

In this context, the purpose of the study was to investigate firstly whether $S$. aureus is not only able to invade but also to proliferate within osteoblasts, secondly to delineate the mechanism of invasion and thirdly to clarify whether rifampicin or gentamicin can inhibit intracellular proliferation and survival of $S$. aureus in the SAOS-2 osteoblast-like cell line in an in vitro infection model.

\section{Materials and Methods}

\section{Bacteria}

Bacterial strains used in this study were $S$. aureus EDCC5055 (Alt et al., 2006) and S. aureus subsp. aureus Rosenbach 1884 (ATCC 12598) (Kreis et al., 2013). MSSA EDCC 5055 is a clinical isolate from a patient with wound infection. The isolate was identified by API biochemical characteristic testing (bioMerieux, Marcy L'Etoile, France) by sequencing the $16 \mathrm{~S}$ rDNA gene, and by specific PCRs to detect the $f e m B$ and coa genes. This strain exhibited strong haemolytic activity and a very strong biofilm formation capacity. S. aureus Rosenbach 1884 is a clinical isolate from a patient with septic arthritis. The minimal inhibitory concentrations (MIC) for rifampicin and gentamicin for both $S$. aureus strains were $\leq 0.5 \mu \mathrm{g} / \mathrm{mL}$. Haemolysin assay was performed as described for Listeria monocytogenes (Domann et al., 1993). Briefly, S. aureus EDCC 5055 was grown overnight in brain heart infusion broth (BHI). Bacterial cultures $(0.2 \mathrm{~mL})$ were inoculated in 10 to $20 \mathrm{~mL}$ of the same medium and incubated at $37^{\circ} \mathrm{C}$ for 6 to $8 \mathrm{~h}$. Samples of $1 \mathrm{~mL}$ of the various cultures were then centrifuged at $10,000 \mathrm{x}$ g for $10 \mathrm{~min}$ at $4{ }^{\circ} \mathrm{C}$, and the clear supernatant, which was supplemented with $10 \mathrm{mM}$ dithiothreitol (DTT), was assayed for haemolytic activity. The concentration of sheep erythrocyte suspension was adjusted to give an A540 of 0.8 at the time of complete lysis. The haemolytic activity titre is expressed in minimal haemolysis units, defined as the reciprocal of the highest dilution at which haemolysis was detected.

Biofilm formation testing of S. aureus EDCC 5055 was based on the ability of the bacteria to form biofilms on polystyrene (PS) plastic, e.g., the development of microcolonies that can be detected macroscopically. Biofilm formation assay was performed as described (O’Toole et al., 1999). Briefly, overnight cultures in tryptic soy broth (TSB) were diluted 1:100 into fresh medium and $200 \mu \mathrm{L}$ of the freshly inoculated medium was dispensed into the wells of a microtitre plate. The inoculated microtitre plate was incubated at $37^{\circ} \mathrm{C}$ for $48 \mathrm{~h}$ without agitation. The liquid cultures were removed and the wells were rinsed twice thoroughly and vigorously with biofilm buffer $\left(2 \mathrm{mM} \mathrm{CaCl} / \mathrm{MgCl}_{2}\right)$ to remove unattached cells.
Two hundred $\mu \mathrm{L}$ of biofilm buffer and $20 \mu \mathrm{L}$ of crystal violet $(\mathrm{CV})$ staining solution $(0.1 \% \mathrm{w} / \mathrm{v} \mathrm{CV}$ in water) were added to detect biofilms by staining. The plates were incubated for $15 \mathrm{~min}$ at room temperature and then rinsed with biofilm buffer to remove residual staining. Bacteria able to form biofilms coated the inner surface of the wells and the microcolonies were visible in purple colour.

Bacteria were grown in brain-heart infusion (BHI) broth. In all experiments, fresh cultures of bacteria, prepared from an overnight culture, were used. Briefly, bacteria were grown in $\mathrm{BHI}$ at $37^{\circ} \mathrm{C}$, harvested in the exponential growth phase and washed twice with phosphate buffered saline (PBS). The pellet was resuspended in PBS and the bacterial concentration was calibrated by optical absorption. Further dilutions were prepared in PBS to obtain required numbers of bacteria for infection.

\section{In vitro invasion assay of SAOS-2 cells and primary osteoblasts}

The SAOS-2 osteoblast-like cell line was grown in Gibco Minimum Essential Medium (MEM) (Life Technologies/Thermo Fisher Scientific, Waltham, MA, USA) supplemented with $10 \%$ foetal calf serum and $1 \%$ non-essential amino acids. Primary human osteoblasts were differentiated from human bone marrow mesenchymal stem cells of human reaming debris in accordance with local ethical approval as previously described (Wenisch et al., 2005). For infection assay, SAOS-2 cells or primary human osteoblasts were cultured to a semi-confluent layer ( $2 \times 10^{5}$ cells $/ \mathrm{mL}$ or $2 \times 10^{4}$ respectively) in 24 -well plates. Bacterial cultures were incubated overnight. Following 1:10 fresh media dilution, bacterial cultures were grown for $2 \mathrm{~h}$ and diluted to an OD of 0.1 with MEM medium. Bacteria were added at a multiplicity of infection (MOI) of 30 per well. After incubation for $30 \mathrm{~min}$, supernatant was discarded and infected cells were washed twice with 1x PBS. MEM was replaced by medium supplemented with $30 \mu \mathrm{g} / \mathrm{mL}$ gentamicin to kill only the remaining extracellular bacteria without affecting the intracellular bacteria (Drevets et al., 1994). Cells were then incubated at $37^{\circ} \mathrm{C}$ for 2, 4, 6 and $24 \mathrm{~h}$. The supernatant fluids were discarded and the cells were washed three times with $1 \mathrm{x}$ PBS and lysed with $0.2 \%$ Triton X-100 in sterile cold distilled water for $20 \mathrm{~min}$. After this, cells were thoroughly mixed to achieve complete lysis. The lysates were diluted 10 times in $1 \mathrm{x}$ PBS and plated onto BHI agar plates using the Auto plate 3000 spiral plating system (Spiral Biotech/ Advanced Instruments, Norwood, MA, USA). After $24 \mathrm{~h}$ of incubation at $37^{\circ} \mathrm{C}$, the number of bacterial colonies was counted and the total colony forming units (cfu) were determined. In order to test the mode of bacterial internalisation, SAOS-2 were treated with cytochalasin D $(2 \mu \mathrm{M}) 2 \mathrm{~h}$ prior to infection. Cytochalasin $\mathrm{D}$ is the major actin depolymerisation agent (Jevon et al., 1999) which disrupts actin microfilaments.

To investigate the effects of antibiotics, SAOS-2 cells were infected with $S$. aureus and after 30 min extracellular bacteria were inactivated by addition of $20 \mathrm{mg} / \mathrm{mL}$ lysostaphin. Thereafter, cells were washed as previously described followed by addition of MEM containing $30 \mu \mathrm{g} /$ $\mathrm{mL}, 100 \mu \mathrm{g} / \mathrm{mL}$ and $200 \mu \mathrm{g} / \mathrm{mL}$ gentamicin or $7.5 \mu \mathrm{g} / \mathrm{mL}$ 
rifampicin and then incubated for a time period of $4 \mathrm{~h}$ and $24 \mathrm{~h}$. Intracellular cfu were determined as detailed above.

\section{Immunofluoresence}

$4 \mathrm{~h}$ after infection with EDCC5055 or Rosenbach 1884 , SAOS-2 cells on glass coverslips were fixed with $3.7 \%$ formaldehyde diluted in $1 \mathrm{x}$ PBS for $10 \mathrm{~min}$ and permeabilised with $0.2 \%(\mathrm{v} / \mathrm{v})$ Triton X-100 in $1 \mathrm{x}$ PBS for $1 \mathrm{~min}$. After rinsing with 1 x PBS, coverslips were incubated with Oregon Green 488 conjugated phalloidin and anti-S. aureus monoclonal antibody (Abcam, Cambridge, UK). Primary antibody was detected by incubation with a $\mathrm{Cy} 3$ conjugated secondary antibody (Dianova, Hamburg, Germany). Samples were examined using an immunofluorescence microscope (Keyence, Neu-Isenburg, Germany) and images were captured and processed using BZ-8000 software (Keyence).

\section{Transmission electron microscopy (TEM)}

SAOS-2 cells were seeded in chamber slides and infected with EDCC5055 for $4 \mathrm{~h}$ as described above. After removing the culture medium, cells were rinsed several times in 0.1 M PBS pH 7.4. The chamber was then detached from the slide, which was cut in pieces and fixed in yellow fix (2\% paraformaldehyde [Carl Roth, Karlsruhe, Germany] and $0.02 \%$ picric acid [Fluka/Sigma-Aldrich, Munich, Germany] in $0.1 \mathrm{M}$ sodium phosphate buffer plus $2 \%$ glutaraldehyde [Merck, Darmstadt, Germany]) for $1 \mathrm{~h}$ at $4{ }^{\circ} \mathrm{C}$. After thorough washing in $0.1 \mathrm{M}$ cacodylate buffer $\mathrm{pH} 7.4$, slides were fixed again in $1 \%$ osmium tetroxide in $0.1 \mathrm{M}$ cacodylate buffer at room temperature, washed and dehydrated through a graded series of ethanol. After two steps of xylene, samples were infiltrated in glycidyl ether 100, formerly known as Epon 812 (and hereafter called "Epon) [Serva, Heidelberg, Germany: $47.5 \%$ glycidyl ether 100 (no. 21045), $20 \%$ 2-dodecenylsuccinic acid anhydride (no. 20755), $31 \%$ methyl nadic anhydride (no. 29452), $1.5 \%$ 2,4,6-Tris(dimethylaminomethyl)phenol (no. 36975)] $+1.5 \%$ DMP 30 (Serva) four times alternating for $10 \mathrm{~min}$ at $55^{\circ} \mathrm{C}$ and for $50 \mathrm{~min}$ in a desiccator at $60 \mathrm{kPa}$. Samples were put in fitting moulds and kept at $55^{\circ} \mathrm{C}$ for $10 \mathrm{~min}$ followed by $15 \mathrm{~min}$ in a desiccator at $60 \mathrm{kPa}$, then for $3 \mathrm{~h}$ at $48^{\circ} \mathrm{C}$ and finally polymerised at $60{ }^{\circ} \mathrm{C}$ for $20 \mathrm{~h}$. After polymerisation and prior to cutting, the plastic slide was removed from the Epon block. Semithin and ultrathin sections were prepared with an Ultracut microtome (Reichert-Jung, Buffalo, NY, USA). Semi-thin sections were stained with toluidine blue, microscopically examined and used for orientation. Ultra-thin sections were contrasted with uranyl acetate (Ultrostain I, Laurylab, Saint-Fons, France) and lead citrate (Ultrostain II, Laurylab) in an Ultrostainer 2168 (LKB, Bromma, Sweden) and analysed with a LEO EM 912 (Zeiss, Oberkochen, Germany). Micrographs were acquired by using a slow scan CCD camera (TRS Sharpeye, Troendle, Moorenwies, Germany) controlled by the software ITEM (Olympus-SIS, Münster, Germany).

\section{Measurement of apoptosis by flow cytometry}

Induction of apoptosis in infected SAOS-2 cells was measured by flow cytometry using the Alexa Fluor 488 annexin V cell apoptosis kit (Invitrogen Life Technologies/ Thermo Fisher Scientific) according to manufacturer's instructions. Annexin V labelled with Alexa Fluor can identify apoptotic cells by binding to phosphatidyl serine (PS), which is exposed on the outer leaflet of the plasma membrane of apoptotic cells. Flow cytometry was performed using a FACS Calibur flow cytometer and further analysed with CELL Quest software (Becton Dickinson, Mountain View, CA, USA).

\section{MTT assay for cell growth determination}

Cytotoxic effects of cytochalasin D, lysostaphin, gentamicin, and rifampicin on SAOS-2 cells were measured using MTT-based cell growth determination kit (Sigma-Aldrich) according to manufacturer instructions. Mitochondrial dehydrogenases of viable cells cleave the tetrazolium ring of MTT solution yielding purple MTT formazan crystals. These crystals were solubilised in acidified isopropanol and the resulting purple solution was spectrophotometrically measured. An increase in the number of viable cells results in an increase in the amount of MTT formazan formed and an enhancement of absorbance.

\section{Statistical analysis}

Data are representative of at least three independent experiments. Significance of the represented data was calculated using an unpaired Student's $t$-test. Data are expressed as mean \pm standard errors (S.E.).

\section{Results}

\section{S. aureus can successfully not only invade but also proliferate inside osteoblasts}

Both $S$. aureus strains (S. aureus EDCC5055 and S. aureus Rosenbach 1884) were found to effectively invade SAOS2 cells as well as primary human osteoblasts (Fig. 1). $2 \mathrm{~h}$ post-infection about $31 \%$ and $64 \%$ of the infection inocula of S. aureus EDCC5055 and S. aureus Rosenbach 1884, respectively, were detected inside SAOS-2 cells while about $63 \%$ and $21 \%$, respectively, could internalise human osteoblasts. Moreover, they could efficiently proliferate within osteoblasts and survive intracellularly over at least $6 \mathrm{~h}$ after infection as the number of intracellular bacteria progressively increased during this time period. Although EDCC5055 showed a lower invasion rate than Rosenbach 1884 in SAOS-2 cells, it demonstrated a higher invasion rate in primary osteoblasts as well as higher replication rates inside both host cells during the first $6 \mathrm{~h}$ postinfection. These findings argue for strain specific invasion and replication rates regarding osteoblasts. However, both strains showed a growth decline $24 \mathrm{~h}$ post-infection. In order to explain this observation, we measured the levels of apoptosis in SAOS-2 cells after infection with S. aureus. Interestingly, we found that $S$. aureus could significantly induce apoptosis in SAOS-2 cells $24 \mathrm{~h}$, but not $4 \mathrm{~h}$, postinfection (Fig. 7). 
(a)

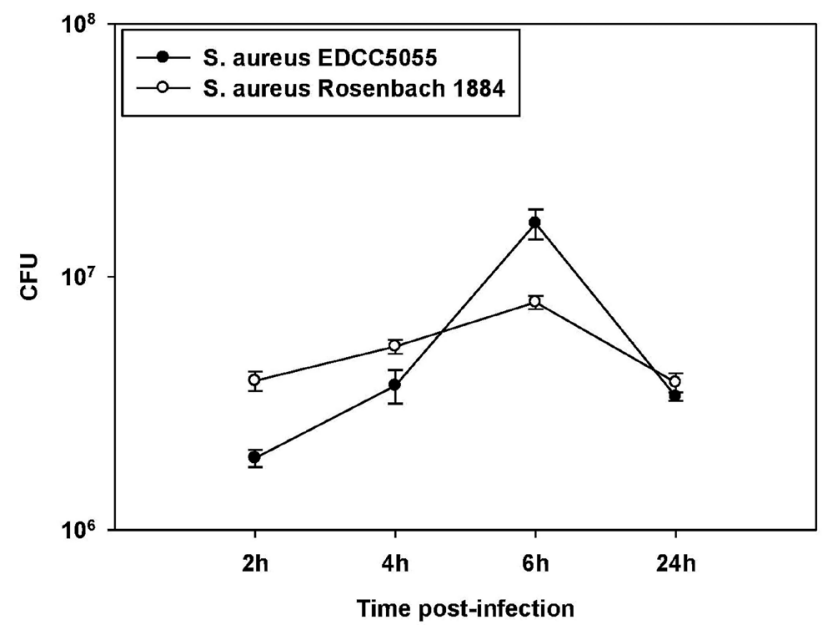

(b)

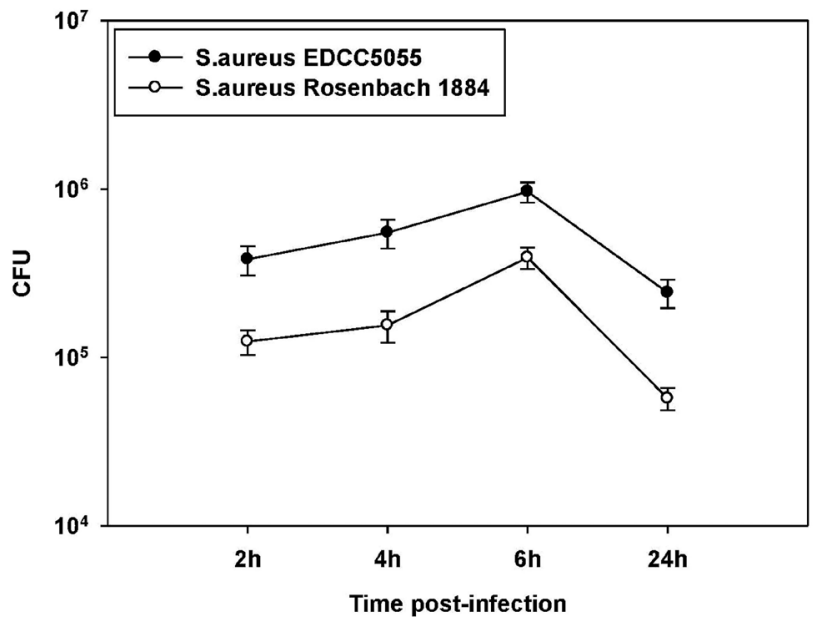

Fig. 1. Invasion and intracellular growth of S. aureus EDCC5055 and S. aureus Rosenbach1884 in the SAOS-2 osteoblast-like cell line (a) or primary human osteoblasts (b). Bacteria infected osteoblasts at a MOI of 30 for 30 min after which gentamicin $(30 \mu \mathrm{g} / \mathrm{mL})$ was added and intracellular bacterial growth was monitored at 2, 4, 6 and $24 \mathrm{~h}$ post-infection.

Fig. 2. Cytochalasin D inhibits $S$. aureus internalisation in SAOS-2 cells. Pre-treatment of SAOS-2 cells with $2 \mu \mathrm{g} / \mathrm{mL}$ cytochalasin D, $4 \mathrm{~h}$ prior to infection with $S$. aureus EDCC5055, inhibited bacterial internalisation $\left({ }^{a} p \leq 0,01\right)$.

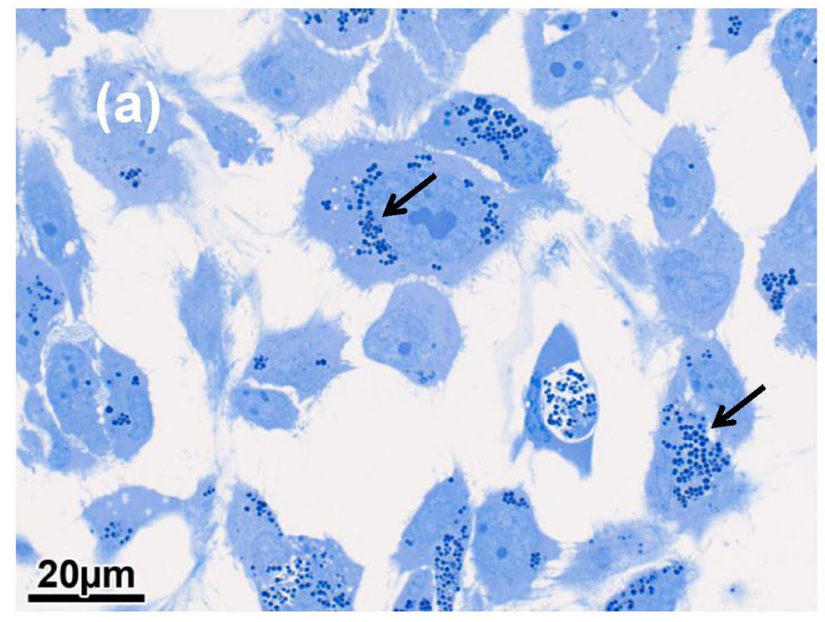

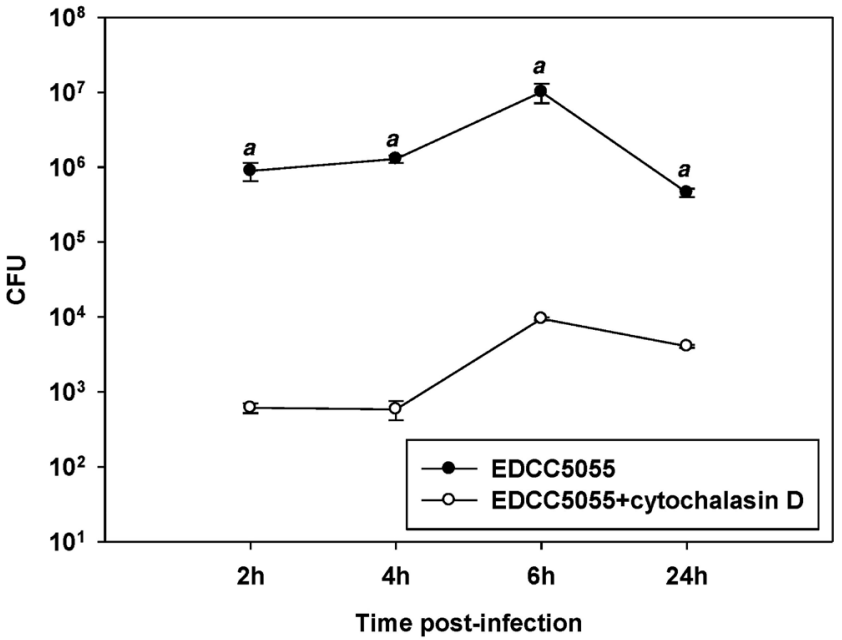

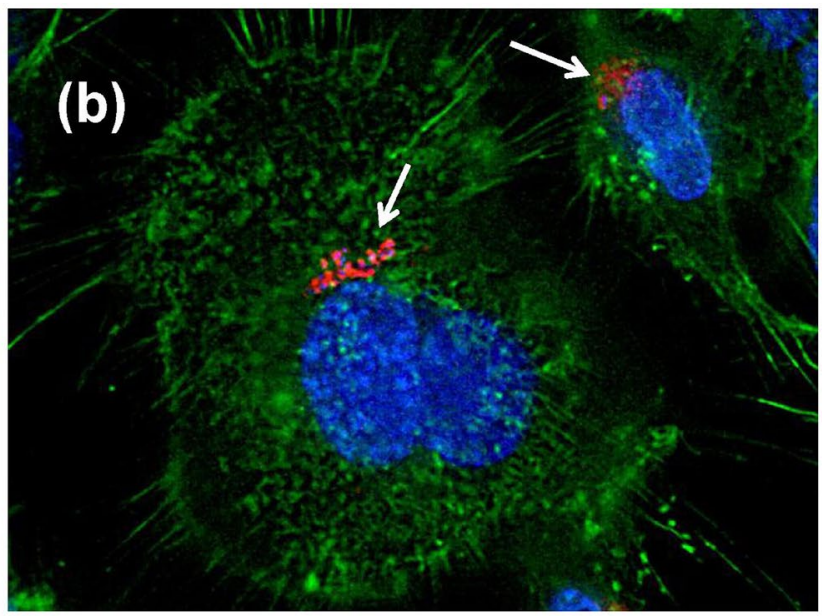

Fig. 3. Internalisation of $S$. aureus in SAOS-2 cells. (a) Intracellular S. aureus Rosenbach1884 (arrows) in a semithin Epon section were stained dark blue by toluidine blue and examined by light microscopy, (b) Intracellular $S$. aureus EDCC5055 could be detected in red inside SAOS-2 cells (arrows) using immunofluorescence microscopy. 

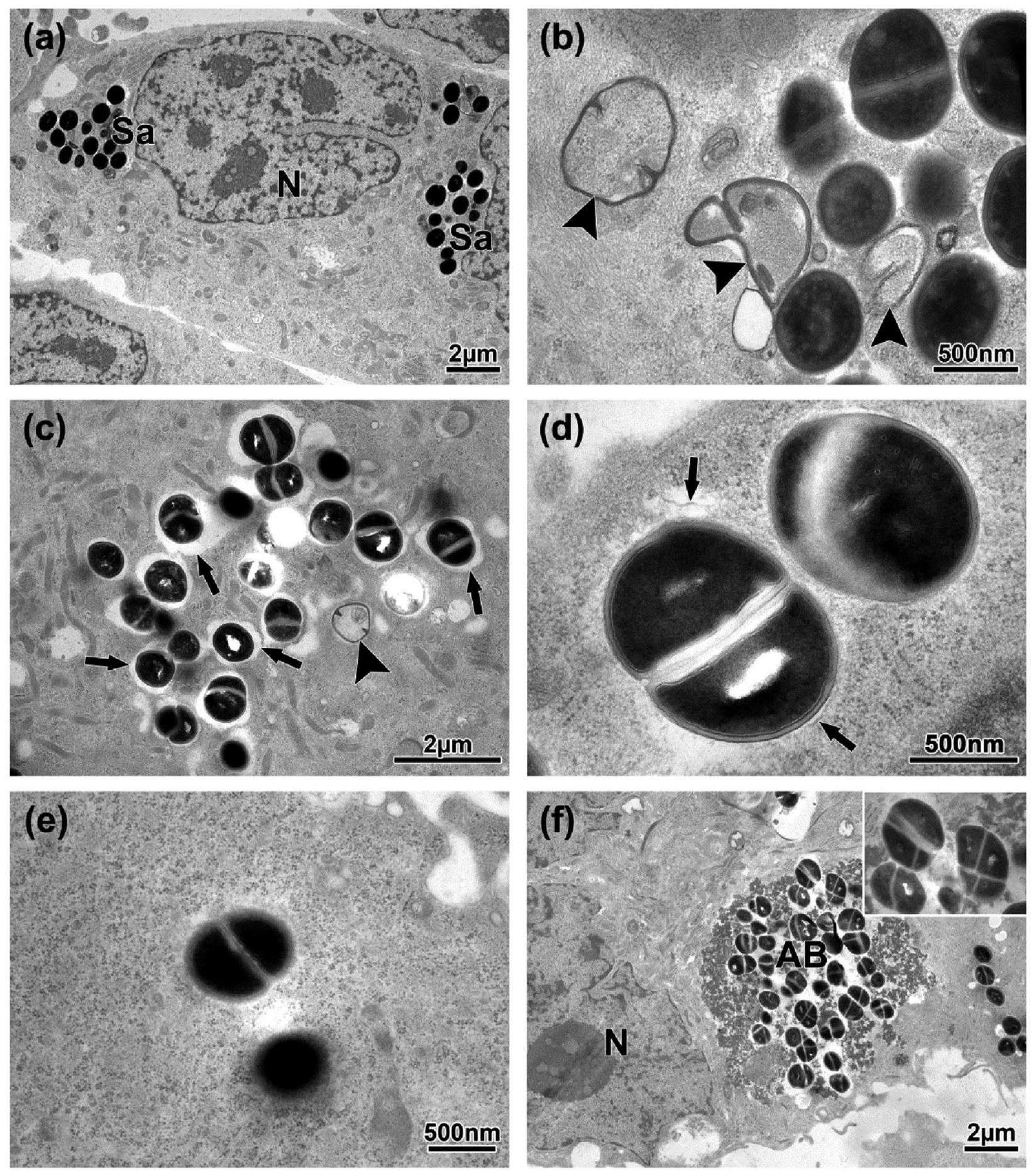

Fig. 4. Intracellular persistence and multiplication of $S$. aureus. (a) Clusters of $S$. aureus EDCC5055 (Sa) are detected by TEM in the cytosol of SAOS-2 cells in the vicinity of the nucleus (N) in SAOS-2 cells, (b) In addition to proliferating bacteria, some damaged bacteria are visible, where cell wall and plasma membrane of $S$. aureus (EDCC5055) remain intact, albeit sometimes deformed, around a disintegrated bacterial cytoplasm (arrowheads), (c) Clusters of intracellular $S$. aureus Rosenbach 1884 were detected by TEM where most bacteria are surrounded by phagosomal/lysosomal membranes (arrows), (d) High magnification of S. aureus Rosenbach 1884 showing residues of phagosomal/lysosomal membranes (arrow), (e) Some bacteria (Rosenbach 1884) are scattered freely in the cytosol, (f) Occasionally intracellular apoptotic bodies (AB) are recognised inside SAOS-2 cells consisting of detritus and lots of proliferating bacteria, showing more than one division septa (inset). 

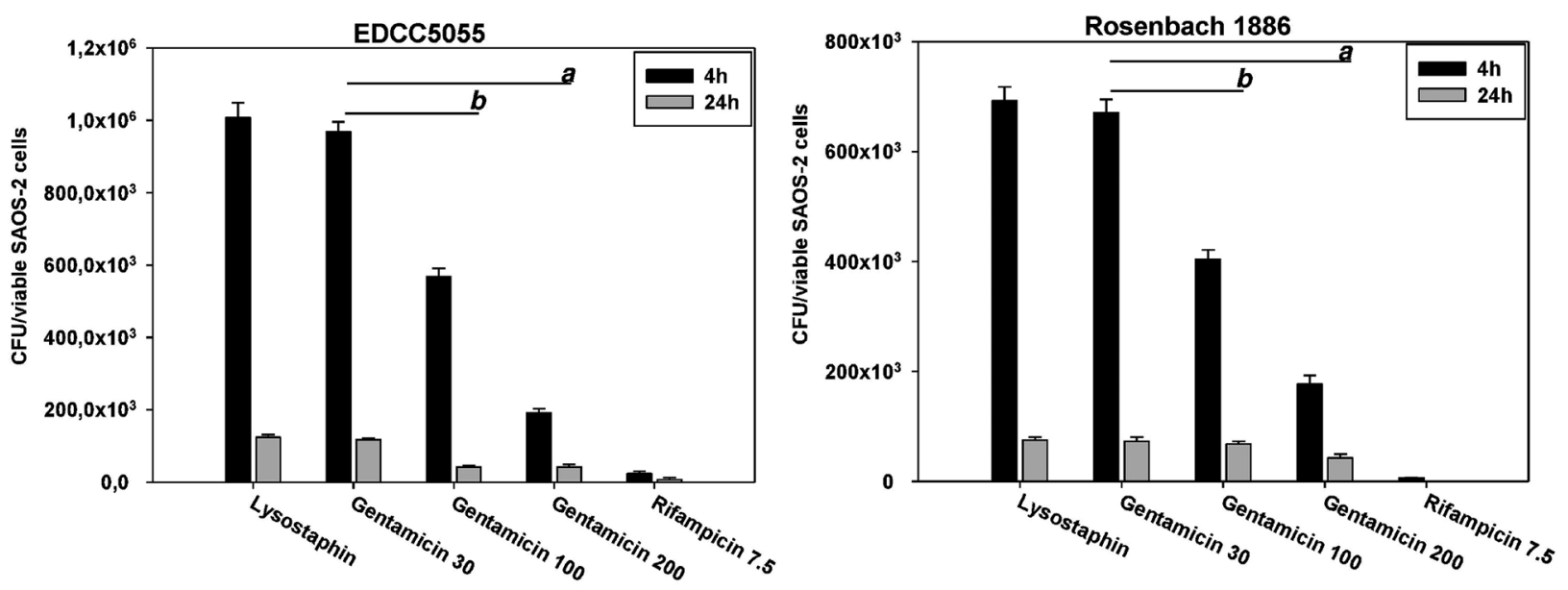

Fig. 5. Effect of antibiotics on intracellular survival of $S$. aureus. SAOS-2 cells were infected either with EDCC5055 or Rosenbach 1884 followed by inactivation of extracellular bacteria with lysostaphin and addition of different concentrations of gentamicin or rifampicin. Viable intracellular bacteria were counted $4 \mathrm{~h}$ and $24 \mathrm{~h}$ post-infection $\left({ }^{a} p \leq 0.01\right.$ gentamicin $30 v s$. gentamicin $200,{ }^{b} p \leq 0.05$ gentamicin $30 v s$. gentamicin 100).

Fig. 6. Effect of antibiotics on SAOS-2 cells viability. SAOS- 2 cells were treated with gentamicin $(30 \mu \mathrm{g} / \mathrm{mL}$ and $200 \mu \mathrm{g} / \mathrm{mL})$, rifampicin $(7.5 \mu \mathrm{g} / \mathrm{mL})$, lysostaphin $(20 \mathrm{mg} / \mathrm{mL})$, or cytochalasin $\mathrm{D}(2 \mu \mathrm{g} / \mathrm{mL})$ for $4 \mathrm{~h}$ or $24 \mathrm{~h}$. Cell viability was determined based on the MTT assay. Data are presented as percent of cell viability compared to cell viability of untreated SAOS-2 cells.

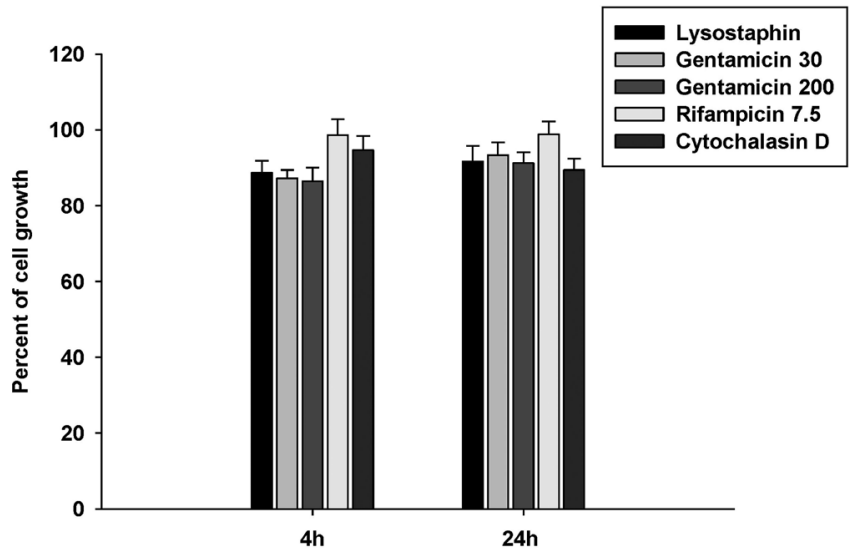

$S$. aureus uses actin rearrangement at the cell surface for cell invasion

In order to investigate the mode of $S$. aureus internalisation into human osteoblasts, SAOS-2 cells were pre-treated with Cytochalasin D $(2 \mu \mathrm{M}) 2 \mathrm{~h}$ prior to infection. A significant reduction of invasion capability of $S$. aureus strains occurred in SAOS-2 cells pre-treated with Cytochalasin D (Fig. 2). Cytochalasin D did not confer cytotoxic effects on SAOS-2 as measured by cell growth MTT assay (Fig. 6).

Microscopic examination of toluidine blue-stained semi-thin Epon sections showed that $S$. aureus can internalise and localise inside SAOS-2 cells (Fig. 3a). Moreover, immunofluorescence microscopy revealed the intracellular persistence of $S$. aureus (Fig. 3b). Compartmentalisation of $S$. aureus inside SAOS-2 cells was more intensively examined by transmission electron microscopy (TEM). Upon entry, a few bacteria were visible inside the SAOS-2 cells forming small clusters of two or three individual bacteria, which rapidly divided and replicated to bigger clusters (Fig. 4a) until multiple bacteria were scattered throughout the cytosol. Damaged phagosomal/lysosomal membrane residues were sometimes visible surrounding individual bacteria (Fig. 4c,d) or clusters of bacteria as well as bacteria lying freely in the cytosol (Fig. 4e). Bacterial damage occurs with recognisable albeit sometimes deformed cell wall and plasma membrane but disintegrated bacterial cytoplasm (Fig. 4b,c). Occasionally, apoptotic bodies containing undefinable cellular detritus and many rapidly dividing bacteria were detected inside infected SAOS-2 cells (Fig. 4f). Both $S$. aureus strains showed under TEM almost the same survival and replication patterns inside SAOS-2 cells.

\section{Rifampicin is highly effective against intracellular $S$. aureus}

A rifampicin concentration of $7.5 \mu \mathrm{g} / \mathrm{mL}$ was able to clear almost all intracellular $S$. aureus $4 \mathrm{~h}$ after infection (Fig. 5). Even after $24 \mathrm{~h}$, no intracellular bacterial growth could be detected.

\section{Only high concentrations of gentamicin kill intracellular $S$. aureus}

As expected, a concentration of $30 \mu \mathrm{g} / \mathrm{mL}$ gentamicin was not able to exhibit an intracellular activity on $S$. aureus $4 \mathrm{~h}$ after infection. Higher concentrations of $100 \mu \mathrm{g} / \mathrm{mL}$ and $200 \mu \mathrm{g} / \mathrm{mL}$, however, showed a significant intracellular effect compared to $30 \mu \mathrm{g} / \mathrm{mL}$ (Fig. 5). This indicates that higher concentrations of gentamicin could penetrate 


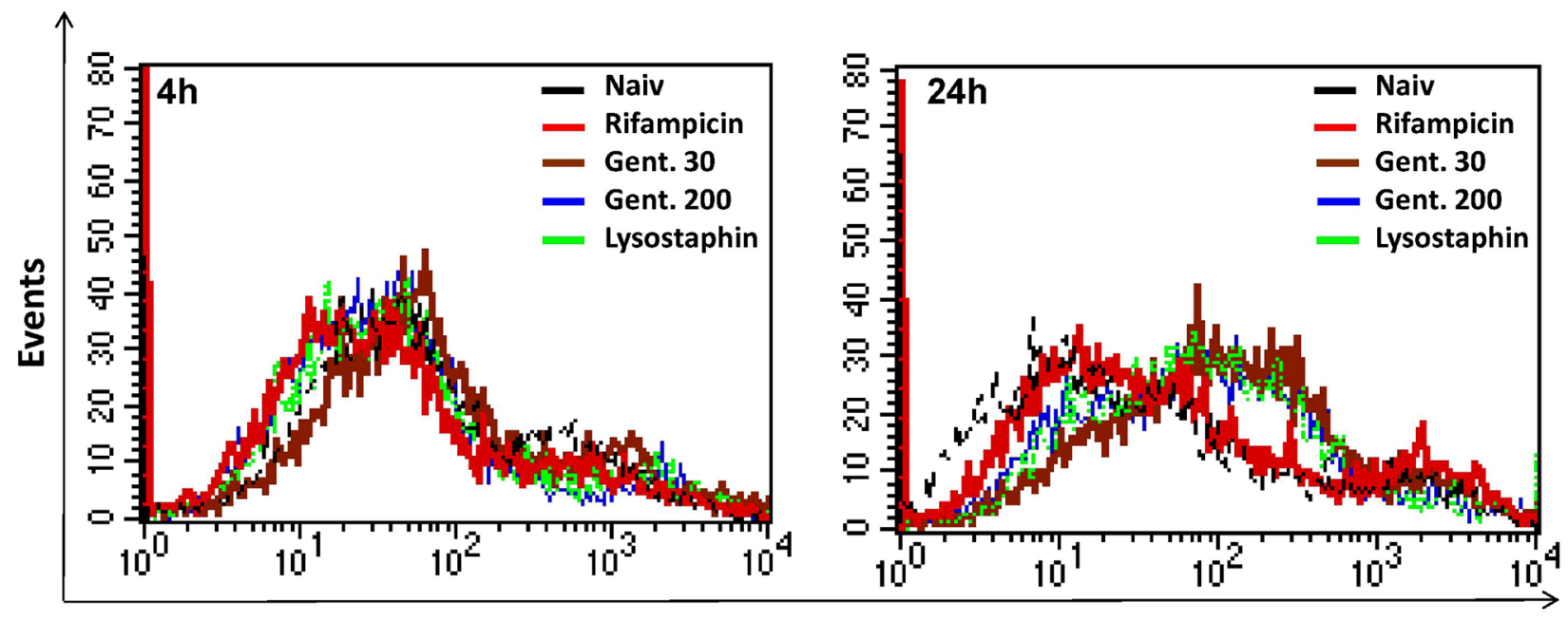

Annexin V flourescence [rel. units]

Fig. 7. Induction of apoptosis in SAOS-2 cells. Cells were infected or not with EDCC5055 then treated with gentamicin, rifampicin, or lysostaphin for $4 \mathrm{~h}$ and $24 \mathrm{~h}$, as shown in the legend of figure 6, and stained with Alexa Fluor 488 annexin V. Binding of annexin V to SAOS-2 cells was analysed by flow cytometry.

the cell membrane of osteoblasts and kill S. aureus in the intracellular compartments. At $24 \mathrm{~h}$ post-infection, the number of isolated intracellular $S$. aureus cfus after treatment with different gentamicin concentrations was comparable. Again, the induction of apoptosis in SAOS2 cells was measured by flow cytometry analysis $4 \mathrm{~h}$ and $24 \mathrm{~h}$ post-infection with $S$. aureus and treatment with lysostaphin, $30 \mu \mathrm{g} / \mathrm{mL}$ gentamicin, $200 \mu \mathrm{g} / \mathrm{mL}$ gentamicin, or $7.5 \mu \mathrm{g} / \mathrm{mL}$ rifampicin. While obvious signs of apoptosis were detected in infected cells pre-treated with lysostaphin and both concentrations of gentamicin $24 \mathrm{~h}$ post-infection, pre-treatment with rifampicin did not result in apoptosis in SAOS-2 cells in comparison to naive uninfected cells (Fig. 7). Moreover, no apoptosis was detected in infected cells treated with lysostaphin, gentamicin, or rifampicin $4 \mathrm{~h}$ post-infection. Indeed, neither of these substances with the doses used in the work showed significant cytotoxic effects on uninfected SAOS-2 cells in the MTT-based cell growth determination assay as more than $85 \%$ of SAOS- 2 cells were viable up to $24 \mathrm{~h}$ after treatment (Fig. 6).

\section{Discussion}

Emerging evidence suggests that Staphylococci are facultative intracellular pathogens able to hijack the host intracellular niches to enhance persistence, thus representing an important pathogenic principle in bone infections (Wright and Nair, 2010). Furthermore, it was shown that non-pathogenic Staphylococci such as $S$. carnosus are unable to efficiently invade osteoblasts (Ellington et al., 2001), indicating that invasion and persistence of $S$. aureus can be linked to its virulence phenotype. Our results demonstrate that $S$. aureus is not only able to invade osteoblasts but also to proliferate within these cells. Both microbiological growth curve assessment and morphological methods such as fluorescence microscopy and TEM indicated intracellular proliferation after invasion of the SAOS-2 cells up to $6 \mathrm{~h}$ post-infection. Although the host cell receptor that initiates $S$. aureus internalisation regarding osteoblasts is not yet identified, this process depends on an actin polymerisation strategy because addition of cytochalasin D significantly abrogates invasion. This finding indicates that $S$. aureus uses an active internalisation machinery to invade osteoblasts. These results are in line with current literature reporting that actin microfilaments play a significant role in the invasion process (Shi and Zhang, 2012).

Following intracellular invasion, the synergistic activity of the cytolytic peptide, staphylococcal $\delta$-toxin and the sphingomyelinase $\beta$-toxin enable the phagosomal escape of Staphylococci in human epithelial as well as in endothelial cells (Giese et al., 2011). Our TEM figures could show binary fission of initial clusters of two or three individual bacteria invading the SAOS- 2 cells that seem to have damaged the surrounding phagosomal membrane and rapidly divide and replicate to bigger clusters scattered freely throughout the cytosol.

Subsequent cell death of host cells by apoptosis (Nuzzo et al., 2000), as discussed above, leads to the release of viable intracellular $S$. aureus which can in turn infect new osteoblasts leading to recurrence of infection. This strategy should have a high clinical relevance as intracellular $S$. aureus remains protected from the action of most antibiotics that are currently used in treatment of bone infections such as $\beta$-lactams, vancomycin, and gentamicin, which cannot penetrate host cell membranes; whereas, in contrast, rifampicin is known to exhibit intracellular antibiotic activity (Carryn et al., 2003). Those observations are confirmed by our in vitro antibiotic testing experiments that demonstrated that $7.5 \mu \mathrm{g} / \mathrm{mL}$ rifampicin efficiently killed almost all bacteria within the first four hours. Concentrations of $30 \mu \mathrm{g} / \mathrm{mL}$ of gentamicin did not show any killing effect on intracellular $S$. aureus, whereas 
higher concentrations of $100 \mu \mathrm{g} / \mathrm{mL}$ and to a larger extent $200 \mu \mathrm{g} / \mathrm{mL}$ were able to significantly reduce the number of bacteria, $4 \mathrm{~h}$ post-infection. Because gentamicin is not able to penetrate host cell membranes, it was hypothesised that it can be partially internalised by the cell through pinocytosis and can enter the same intracellular compartment as phagocytosed bacteria (Drevets et al., 1994). On the other hand, the mechanism of intracellular accumulation of rifampicin remains obscure. However, rifampicin has originally demonstrated bactericidal activity against slow and intermittently growing intracellular Mycobacterium tuberculosis (Van Ingen et al., 2013). The reason for the reduction in intracellular bacterial survival $24 \mathrm{~h}$ after treatment, with each antibiotic, was explained in this study. Rifampicin could efficiently and quickly kill intracellular $S$. aureus. As a result, no bacteria-related apoptosis was recorded (Fig. 7). On the other hand gentamicin even at a dose of $200 \mu \mathrm{g} / \mathrm{mL}$ was not able to efficiently eradicate intracellular $S$. aureus, which could resume its proliferation over $24 \mathrm{~h}$ post-infection thus being able to induce apoptosis in SAOS-2 cells making intracellular bacteria accessible to the action of extracellular antibiotics. Indeed, induction of apoptosis by $S$. aureus was previously documented in different human cells (Nuzzo et al., 2000; Haslinger et al., 2003; Genestier et al., 2005). It is also noteworthy to mention that the doses of gentamicin and rifampicin used in this study did not confer noticeable cytotoxicity in SAOS-2 cells up to $24 \mathrm{~h}$ after treatment. However, a recent study has demonstrated that gentamicin concentrations up to $100 \mu \mathrm{g} / \mathrm{mL}$ as well as a rifampicin concentration of $10 \mu \mathrm{g} / \mathrm{mL}$ cause less than $25 \%$ decrease in viability of human osteoblasts $14 \mathrm{~d}$ after treatment while $200 \mu \mathrm{g} / \mathrm{mL}$ gentamicin achieved a 26-49 \% decrease in viable cell number in the same time period (Rathbone et al., 2011). Based on our data, high local gentamicin concentrations of at least $100 \mu \mathrm{g} / \mathrm{mL}$ should be achieved in a clinical setting to significantly reduce the bacterial load in vivo. This concentration, however, is not achievable with systemic administration of gentamicin, where concentrations of $1-10 \mu \mathrm{g} / \mathrm{mL}$ have been reported (Sande and Mandell, 1980; de Klaver et al., 2012). For local delivery of gentamicin at the site of bone infection different peak level concentrations are reported. Walenkamp et al. (1986) found high local concentrations with values of up to $500 \mu \mathrm{g} / \mathrm{mL}$ at the site of infection, in a clinical study, on the first day after administration of gentamicin beads manufactured with $2 \mathrm{~g}$ of gentamicin and $40 \mathrm{~g}$ of PMMA bone cement. In another clinical trial, Jenny and Tagland (1980) reported peak concentrations of $80 \mu \mathrm{g} / \mathrm{mL}$ in the wound secretion at the site of infection when using 180 gentamicin-PMMA beads. Moreover, up to $440 \mu \mathrm{g} / \mathrm{mL}$ of gentamicin were measured in the total drainage fluid during the first day after surgical debridement and PMMA application in 188 patients with acute or chronic osteomyelitis (Jenny et al., 1995). Anagnostakos et al. (2009) compared gentamicin and vancomycin concentrations after the use of PMMA spacers with $80 \mathrm{mg}$ of PMMA, $1 \mathrm{~g}$ of gentamcin and $4 \mathrm{~g}$ of vancomycin versus beads using $40 \mathrm{mg}$ PMMA, $0.5 \mathrm{~g}$ of gentamicin and $2 \mathrm{~g}$ of vancomycin in a clinical study with 28 patients. Peak mean concentrations of gentamicin on postoperative day 1 were $116 \mu \mathrm{g} / \mathrm{mL}$ for beads (12-
$371 \mu \mathrm{g} / \mathrm{mL}) v s .21 \mu \mathrm{g} / \mathrm{mL}(0.7-39 \mu \mathrm{g} / \mathrm{mL})$ for spacers with high inter-individual variability. In summary, gentamicin PMMA beads seem to achieve concentrations of more than $100 \mu \mathrm{g} / \mathrm{mL}$, which can be assumed to have an inhibitory effect on intracellular bacterial cfu in osteoblasts as evidenced in our study.

In conclusion, the current study shows that $S$. aureus is not only able to invade but also to proliferate within osteoblasts. Invasion seems to be associated with actin rearrangement at the cell surface. Rifampicin with local concentrations of $7.5 \mu \mathrm{g} / \mathrm{mL}$ is effective in intracellular eradication of $S$. aureus whereas gentamicin levels have to reach a local concentration of at least $100 \mu \mathrm{g} / \mathrm{mL}$ to have a significant intracellular effect.

\section{References}

Ahmed S, Meghji S, Williams RJ, Henderson B, Brock JH, Nair SP (2001) Staphylococcus aureus fibronectin binding proteins are essential for internalisation by osteoblasts but do not account for differences in intracellular levels of bacteria. Infect Immun 69: 28722877.

Alt V, Bitschnau A, Osterling J, Sewing A, Meyer C, Kraus R, Meissner SA, Wenisch S, Domann E, Schnettler R (2006) The effects of combined gentamicin-hydroxyapatite coating for cementless joint prostheses on the reduction of infection rates in a rabbit infection prophylaxis model. Biomaterials 27: 4627-4634.

Anagnostakos K, Wilmes P, Schmitt E, Kelm J (2009) Elution of gentamicin and vancomycin from polymethylmethacrylate beads and hip spacers in vivo. Acta Orthop 80: 193-197.

Barth RE, Vogely HC, Hoepelman AI, Peters EJ (2011) 'To bead or not to bead?' Treatment of osteomyelitis and prosthetic joint-associated infections with gentamicin bead chains. Int J Antimicrob Agents 38: 371-375.

Carryn S, Chanteux H, Seral C, Mingeot-Leclercq MP, Van Bambeke F, Tulkens PM (2003) Intracellular pharmacodynamics of antibiotics. Infect Dis Clin North Am 17: 615-634.

de Klaver PA, Hendriks JG, van Onzenoort HA, Schreurs BW, Touw DJ, Derijks LJ (2012) Gentamicin serum concentrations in patients with gentamicin-PMMA beads for infected hip joints: a prospective observational cohort study. Ther Drug Monit 34: 67-71.

Domann E, Wehland J, Niebuhr K, Haffner C, Leimeister-Wächter M, Chakraborty T (1993) Detection of a Prfa-independent promoter responsible for listeriolysin gene expression in mutant Listeria monocytogenes strains lacking the PrfA regulator. Infect Immun 61: 3073-3075.

Drevets DA, Canono BP, Leenen PJ, Campbell PA (1994) Gentamicin kills intracellular Listeria monocytogenes. Infect Immun 62: 2222-2228.

Edwards AM, Potter U, Meenan NA, Potts JR, Massey RC (2011) Staphylococcus aureus keratinocyte invasion is dependent upon multiple high affinity fibronectin-binding repeats within FnBPA. PLoS One 6: e18899.

Ellington JK, Elhofy A, Bost KL, Hudson MC (2001) Involvement of mitogen-activated protein kinase pathways 
in Staphylococcus aureus invasion of normal osteoblasts. Infect Immun 69: 5235-5242.

Fraunholz M, Sinha B (2012) Intracellular Staphylococcus aureus: live-in and let die. Front Cell Infect Microbiol 2: 43.

Genestier AL, Michallet MC, Prévost G, Bellot G, Chalabreysse L, Peyrol S, Thivolet F, Etienne J, Lina G, Vallette FM, Van enesch F, Genestier L (2005) Staphylococcus aureus Panton Valentine leukocidin directly targets mitochondria and induces Bax-independent apoptosis of human neutrophils. J Clin Invest 115: 3117 3127.

Giese B, Glowinski F, Paprotka K, Dittmann S, Steiner T, Sinha B, Fraunholz MJ (2011) Expression of delta-toxin by Staphylococcus aureus mediates escape from phagoendosomes of human epithelial and endothelial cells in the presence of beta-toxin. Cell Microbiol 13: 316-329.

Hamza T, Dietz M, Pham D, Clovis N, Danley S, Li B (2013) Intra-cellular Staphylococcus aureus alone causes infection in vivo. Eur Cell Mater 25: 341-350.

Haslinger B, Strangfeld K, Peters G, Schulze-Osthoff K, Sinha B (2003) Staphylococcus aureus alpha-toxin induces apoptosis in peripheral blood mononuclear cells: role of endogenous tumour necrosis factor-alpha and the mitochondrial death pathway. Cell Microbiol 5: 729-741.

Jarry TM, Memmi G, Cheung AL (2008) The expression of alpha-haemolysin is required for Staphylococcus aureus phagosomal escape after internalisation in CFT-1 cells. Cell Microbiol 10: 1801-1814.

Jenny C, Tagland G (1980) Lokale knocheninfektionsbehandlung mit gentamycin-PMMAkugelketten (Local treatment of bone infection by gentamycin-PMMA bead chains). Beitr Orthop Traumatol 27: 442-448.

Jenny JY, Jenny G, Lambert J, Gaudias J, Kempf I (1995) Utility of measurement of gentamicin release from PMMA beads in wound drainage fluid after in-vivo implantation. Acta Orthop Belg 61: 10-13.

Jevon M, Guo C, Ma B, Mordan N, Nair SP, Harris M, Henderson B, Bentley G, Meghji S (1999) Mechanisms of internalisation of Staphylococcus aureus by cultured human osteoblasts. Infect Immun 67: 2677-2681.

Kintarak S, Whawell SA, Speight PM, Packer S, Nair SP (2004) Internalisation of Staphylococcus aureus by human keratinocytes. Infect Immun 72: 5668-5675.

Kreis CA, Raschke MJ, Roßlenbroich SB, TholemaHans N, Löffler B, Fuchs T (2013) Therapy of intracellular Staphylococcus aureus by tigecyclin. BMC Infect Dis 13: 267.

Nuzzo I, Sanges MR, Folgore A, Carratelli CR (2000) Apoptosis of human keratinocytes after bacterial invasion. FEMS Immunol Med Microbiol 27: 235-240.

O'Toole GA, Pratt LA, Watnick PI, Newman DK, Weaver VB, Kolter R (1999) Genetic approaches to study of biofilms. Methods Enzymol 310: 91-109.

Rathbone CR, Cross JD, Brown KV, Murray CK, Wenke JC (2011) Effect of various concentrations of antibiotics on osteogenic cell viability and activity. J Orthop Res 29: 1070-1074.

Sande MA, Mandell GL (1980) Antimicrobial agents - the aminoglycosides. In: Goodman and Gilman's The
Pharmacological Basis of Therapeutics, 6th edn (Gilman AG, Goodman LS, Gilman A, eds), Macmillan Publishing Co., New York, NY, p. 1175.

Sendi P, Proctor RA (2009) Staphylococcus aureus as an intracellular pathogen: the role of small colony variants. Trends Microbiol 17:54-58.

Shi S, Zhang X (2012) Interaction of Staphylococcus aureus with osteoblasts (Review). Exp Ther Med 3: 367370 .

Van Ingen J, Hoefsloot W, Mouton JW, Boeree MJ, van Soolingen D (2013) Synergistic activity of rifampicin and ethambutol against slow-growing nontuberculous mycobacteria is currently of questionable clinical significance. Int J Antimicrob Agents 42: 80-82.

Walenkamp GH, Vree TB, van Rens TJ (1986) Gentamicin-PMMA beads. Pharmacokinetic and nephrotoxicological study. Clin Orthop Relat Res 205: 171-183.

Wenisch S, Trinkaus K, Hild A, Hose D, Herde K, Heiss C, Kilian O, Alt V, Schnettler R (2005) Human reaming debris: a source of multipotent stem cells. Bone 36: 74-83.

Wright JA, Nair SP (2010) Interaction of Staphylococci with bone. Int J Med Microbiol 300: 193-204.

\section{Discussion with Reviewers}

F. Moriarty: This significance of this formal demonstration of $S$. aureus proliferation within SAOS-2 osteoblast-like cells would be strengthened by demonstrating that $S$. aureus also proliferates in primary osteoblasts (human bone marrow MSCs or rodent calvarial osteoblasts).

Authors: This is a valuable suggestion. We have examined the intracellular growth of both $S$. aureus strains in primary osteoblasts where they showed intracellular growth kinetics comparable to those presented in SAOS-2 cells (Fig. 1b).

E. Schwarz: Why did you not look at longer term incubation of the osteoblasts? You surmise that apoptosis occurs with this cell line, following successful colonisation of the osteoblasts with the bacteria. However, this would be better elucidated if the osteoblasts were followed over a prolonged period. Is there a reason you did not do this? Is $24 \mathrm{~h}$ (for a prokaryote in planktonic phase, a 3 to 4 time generational cycle) enough time to draw this conclusion? Authors: Induction of apoptosis in SAOS-2 cells following infection with $S$. aureus was examined by FACS analysis $4 \mathrm{~h}$ and $24 \mathrm{~h}$ after infection. While $4 \mathrm{~h}$ after infection no apoptosis could be measured in SAOS-2 cells, significant numbers of apoptotic cells were shown $24 \mathrm{~h}$ after infection. $48 \mathrm{~h}$ after infection, more than $80 \%$ SAOS- 2 cells showed microscopic apoptotic morphology such as rounding, vacuolisation of cytoplasm as well as detachment from culture plates. This finding is mainly attributed to the successful proliferation of $S$. aureus inside SAOS-2 cells.

Reviewer III: Is it possible to perform actin fluorescence staining to monitor the effect of cytochalasin on internalisation of bacteria?

Authors: It is not possible in our facilities to monitor the effect of cytochalasin on bacterial internalisation 
by fluorescence microscopy. However, the action of cytochalasin D as an actin depolymerisation agent in various eukaryotic cell lines was established in many studies (Jevon et al., 1999; Shi and Zhang, 2012, text references).

Reviewer III: The viability data indicates a maximum bacterial number at $6 \mathrm{~h}$, yet the antibiotic evaluation was done at 4 and $24 \mathrm{~h}$. Is there a reason that it was not measured at $6 \mathrm{~h}$ ?

Authors: Both time points of 4 and $6 \mathrm{~h}$ are located in the logarithmic growth phase of intracellular $S$. aureus where S. aureus still actively divides and proliferates. We have additionally measured the intracellular survival $6 \mathrm{~h}$ after antibiotics addition. The effects of antibiotic treatments on $S$. aureus intracellular survival at this time point were very close to those observed after $4 \mathrm{~h}$.

Reviewer III: The reduction in viable bacteria at $24 \mathrm{~h}$ is an open question in many regards. Is this correlated with apoptosis of the osteoblasts? Is the rate of cell death recorded and equal amongst groups? Are the bacteria proliferating in dead osteoblasts, but not in viable ones?

Reviewer IV: Since apoptosis is an essential part of the explanation, it would have been useful to show that cells with $S$. aureus at $24 \mathrm{~h}$ indeed were apoptotic. Conversely, wouldn't this have resulted in much higher levels of reduction of the bacterial numbers, more or less equal to what was observed with rifampicin?

Authors: These are actually pivotal questions to explain the relation between SAOS-2 cells viability and survival of intracellular S. aureus. Induction of apoptosis was measured in SAOS-2 cells pre-treated with lysostaphin, $30 \mu \mathrm{g} / \mathrm{mL}$ gentamicin, $200 \mu \mathrm{g} / \mathrm{mL}$ gentamicin, $7.5 \mu \mathrm{g} / \mathrm{mL}$ rifampicin or left untreated. This measurement was carried out $4 \mathrm{~h}$ and $24 \mathrm{~h}$ after infection with $S$. aureus. When compared with untreated cells, we have found out that all SAOS- 2 cells pre-treated with different drugs did not show induction of apoptosis $4 \mathrm{~h}$ after infection. However, after $24 \mathrm{~h}, \mathrm{SAOS}-2$ cells pre-treated with lysostaphin, $30 \mu \mathrm{g} /$ $\mathrm{mL}$ gentamicin and $200 \mu \mathrm{g} / \mathrm{mL}$ gentamicin have shown induction of apoptosis while pre-treatment with $7.5 \mu \mathrm{g} /$ $\mathrm{mL}$ rifampicin revealed apoptotic levels similar to naïve untreated cells. These interesting findings strengthened our hypothesis that induction of apoptosis in SAOS-2 cells is directly correlated with the intracellular bacterial load. Because rifampicin is very effective in rapid killing of intracellular bacteria as shown $4 \mathrm{~h}$ after infection, intracellular bacterial load was very low and subsequently not be able to induce apoptosis. On the other hand, pretreatment with only lysostaphin or the 2 different doses of gentamicin was not sufficient to effectively eradicate the intracellular $S$. aureus giving the bacteria a chance to divide and resume their proliferation over the $24 \mathrm{~h}$ postinfection with subsequent induction of apoptosis. As a result, cell membrane integrity was compromised and the membrane becomes permeable, allowing the extracellular antibiotics or lysostaphin to reach the intracellular $S$. aureus and kill them.
Reviewer III: In Fig. 4, it is difficult to identify the damaged lysosomal membrane mentioned. Are the authors convinced that these features are damaged membranes? Some explanation of the image would be helpful.

Reviewer IV: Where in Fig. 4 are there examples shown of what an intact lysosomal membrane and disintegrating bacteria look like? Such information would be a useful addition to the figure. What is the evidence that the bacteria are actually inside a lysosomal compartment? Have any lysosomal markers been identified? In the caption to Fig. 4 , this is more correctly designated as a phagosomal/ lysosomal membrane.

Authors: Intensive TEM examinations have been carried out in order to demonstrate different stages of intracellular S. aureus persistence and proliferation inside SAOS-2 cells, namely the freely scattered live dividing and sometimes disintegrated S. aureus in the cytosol, as well as the location of bacteria inside either intact or incomplete phagosomal/ lysosomal membranes. Unfortunately, it was not possible under TEM analysis to specify lysosomal markers. So, the host cell membranes that surround bacteria in the cytosol were designated as phagosomal/lysosomal membranes.

Reviewer III: Studies have also shown that gentamicin does not kill intracellular bacteria and that rifampicin does (e.g., Kreis et al., 2013, text reference). Please comment! Authors: Indeed, we aimed to examine the ability of these antibiotics to kill intracellular $S$. aureus within a relatively short time period ( $4 \mathrm{~h}$ ) which was not shown in the study of Kreis et al., where the effect of antibiotic treatment was measured first $24 \mathrm{~h}$ after treatment. We could show that rifampicin was able to eradicate intracellular $S$. aureus only $4 \mathrm{~h}$ after treatment.

Reviewer III: Does a high concentration of gentamicin kill osteoblasts? If so, this may explain the result (see Rathbone et al., 2011, text reference)!

Authors: We appreciate this observation. The highest concentration of gentamicin used in this study $(200 \mu \mathrm{g} / \mathrm{mL})$ was able to keep more than $85 \%$ of SAOS-2 cells viable up to $24 \mathrm{~h}$ post-treatment when compared to untreated cells (Fig. 6).

Reviewer IV: It is a bit strange to use gentamicin for extracellular killing, when the objective of the study is to analyse its intracellular potential. Please comment!

Authors: It is well known that gentamicin at a concentration of $30 \mu \mathrm{g} / \mathrm{mL}$ is not able to gain access into the intracellular compartments of epithelial cells. It is thus usually used as an extracellular bacterial killer in in vitro performed infection assays, for not only $S$. aureus but also other known intracellular bacteria such as Listeria monocytogenes in different epithelial and phagocytic cell lines. (Drevets et al., 1994; Jevon et al., 1999; Ellington et al., 2001). For this reason, this concentration was used in antibiotics killing assays as a negative control.

Reviewer IV: Referring to the Discussion, does this mean there has to be a receptor? Isn't actin rearrangement a general process during phagocytosis? Inhibition of this 
internalisation by cytochalasin D is not that surprising in that view.

Authors: We agree with the reviewer that inhibition of internalisation by cytochalasin $\mathrm{D}$ is not a new observation. However, we wanted to clarify that the receptor that initiates active internalisation event of $S$. aureus in nonphagocytic epithelial cells is not yet discovered.

Reviewer IV: Referring to the Discussion, is there any information on the gentamicin release from the Synthes genta-coated intramedullary nail?

Authors: To our knowledge, no study has yet examined this issue.

Reviewer IV: Referring to the Discussion, what were the success rates of PMMA beads? Are they sufficient for longer term protection?

Authors: The current studies have focused on measuring local antibiotic concentrations released from PMMA spacers while success rates were not studied.

Reviewer IV: Although Fig. 5 may give the readers the impression that there is a real large difference between 4 and $24 \mathrm{~h}$, it is actually only maximally a 5-fold difference. Please comment!

Authors: The difference in cfu between $4 \mathrm{~h}$ and $24 \mathrm{~h}$ is statistically significant as calculated by Student's $t$-test and analysis of variance $(p \leq 0.05)$.

Reviewer IV: Might apoptosis in vivo also play a role in making these bacteria accessible to antibiotics again?

Authors: This possibility, if apoptosis can make bacteria accessible to antibiotics in vivo, needs to be experimentally confirmed. However, bacteria released from apoptotic cells usually use the strategy of invading the neighbour cells in order to remain protected from the action of extracellular antibacterial factors. The major known mechanism for killing bacteria through apoptosis is that apoptotic cells release chemotactic factors that act as signals for professional phagocytic cells, mainly neutrophils, which become active and migrate into the site of infection thus engulfing the apoptotic cells including infecting bacteria. It is noteworthy to mention that one of the goals of this study is to determine the amount of antibiotic that is able to early eradicate intracellular bacteria before signs of apoptosis appear. 